\title{
Los pasquines en el Perú (siglos XVIII y XIX)
}

Recibido: 04 de diciembre de 2011

Aceptado: 31 de julio de 2012

Publicado: 31 de octubre de 2012
Carlos Cornejo Quesada

ccornejo@comunicaciones.usmp.edu.pe

Universidad de San Martín de Porres (Perú)

Resumen: Después de mediados del siglo XVIII, el Virreinato del Perú inició un conjunto de reformas administrativas, acorde a los requerimientos de la monarquía borbónica española. Estas reformas afectaron a los diversos sectores sociales, principalmente criollos, mestizos e indios. Ello trajo consigo un conjunto de protestas y rebeliones, muchas de las cuales se expresaron, entre otros, en los pasquines anónimos contra las autoridades españolas, a diferencia de los periódicos oficiales que se caracterizaron por no hacer conocer los malestares y las rebeliones sociales que se extendieron en el Alto y Bajo Perú hasta los inicios del siglo XIX.

Palabras clave: Historia de los medios de comunicación social en el Perú, pasquines, periodismo político en el Perú.

Abstract: After mid-eighteenth century the Viceroyalty of Peru began a series of administrative reforms in an effort to streamline the needs of the Spanish Bourbon Monarchy. These reforms affected different social sectors, mainly "criollos", "mestizos" and indians. This will bring with it a series of protests and rebellions, many of which were expressed, among others, in anonymous Fliers against the Spanish Authorities, unlike the official newspapers that do not meet characterized by malaise and social rebellions that spread in Upper and Lower Peru until the early nineteenth century.

Key words: History of Mass Media in Peru, Fliers, Peru Political Journalism. 


\section{Introducción}

Los pasquines son medios de comunicación escritos de carácter anónimo. La mayor parte de estos surgió en el sur andino del Perú, manifestando su poder en la conciencia y en la práctica social contra las autoridades de turno del siglo XVIII y comienzos del siglo XIX.

Los pasquines del siglo XVIII fueron un medio de comunicación anónimo y breve, cuyos mensajes amenazantes y hasta infames estaban dirigidos contra alguna autoridad política o administrativa de turno. Se presentaron como escritos públicos con una rica y sugerente fuente de información social, política y cultural. Asimismo, conformaron un repertorio documental importante que traslucieron conflictos sociales, protestas y aspiraciones en escenarios locales o regionales.

Los pasquines fueron escritos ${ }^{1}$ que expresaron los malestares sociales, mediante la opinión y la crítica, enfatizando su afán contestatario contra algo o alguien. Los pasquines tuvieron claros propósitos de protesta, sin dejar de ser persuasivos e incluso hasta subversivos.

El estudio del pasquín demanda optar por una estrategia para esclarecer la inmanencia textual, sin perder sus efectos sociales, en un horizonte comprensivo y explicativo cualitativamente para hallar los rasgos y características comunes. Esta estrategia metodológica obliga inductivamente asediar los hechos en conjuntos intertextuales, cuyas homologaciones y paralelismos permiten conocer los significados del "pasquín" en su entorno histórico, ayudando a revelar su existencia, necesidad y proyección en un ámbito contradictorio y conflictivo históricamente.

Desde antes de mediados del siglo XVIII, las publicaciones impresas adquirieron reputación como fuente y testimonio de verdad histórica, contrastando con el masivo analfabetismo indígena y la cultura oral expresada en lenguas vernaculares (quechua y aymara), además de la comunicación informal escrita como ocurrió con los pasquines del

1 Existen diversas historias acerca de la antigüedad o el origen del término pasquín. Se sabe que es muy antiguo en el mundo occidental. Según las versiones existentes, el pasquín se remonta a la época del Imperio romano con la figura de un gladiador llamado Pasquino. A su muerte, se le erigió una estatua cerca del Coliseo Romano, lugar en donde había peleado y ganado muchas glorias. Por aquellos años se acostumbraba a colocar líbelos satíricos en el pedestal de la estatua. Con el correr del tiempo, este nombre se convirtió en sinónimo de sátiras al poder establecido. También existe otra versión: en el Vaticano existió una tienda administrada por un tal Pasquino, hombre imprudente, chismoso y contador de historias. Si alguien deseaba conocer algo del lugar, se recurría a este personaje para obtener la información deseada. Su nombre fue conocido rápidamente como sinónimo de murmuraciones. Tras su muerte, se hizo una estatua de mármol en su honor. El Papa la hizo colocar en una columna muy cerca de la vieja tienda del chismoso y alguien comenzó a llamarla "Pasquino". El hecho es que todo lo que se pegaba en ese objeto era una "pasquinada". Y "pasquino" pasó al castellano como "pasquín" y sus autores fueron conocidos como "pasquineros" (cf. Gargurevich, 2002). En el siglo XVI, Felipe II hizo sentir su poder en Flandes a través del cardenal borgoñés Antonio Perrenot de Granvela, quien mostró su carácter despótico al marginar a la nobleza flamenca de las grandes decisiones. Pronto aparecieron pasquines en contra del cardenal, aunque este respondió acusando a los nobles locales ante el Rey de ser instigadores y herejes (Lozada, 2008: 32-33). Desde los inicios del siglo XVIII, siguieron proliferando pasquines y líbelos; teniendo como contraparte, la respuesta de los afectados con otros pasquines. Esta guerra de pasquines se hizo visible y constante en España, haciendo que el monarca emitiera un edicto (24/XII/1707) castigando con duras penas a los autores de los pasquines sediciosos que se colocaban en plazas y calles de Barcelona. Esta prohibición sirvió, según Gonzáles Cruz (2009: 84) para entibiar la fidelidad de sus vasallos. Décadas después, los pasquines proliferaron en Navarra. 
Alto y Bajo Perú. Sin embargo, poco después de ese período, gran parte de los pasquines manifestaron comportamientos antirreformistas y antifiscales, antes que cualquier otra intención o práctica anticolonial. Sólo cumplieron la función de protesta y acusación crítica y hasta injuriosa contra las autoridades coloniales. En este ámbito sociopolítico, de múltiples tensiones sociales, los pasquines constituyeron una estrategia comunicativa al mostrar la protesta y hasta la sedición, dejando abierta una posible conciliación o arreglo a la mala gestión de las autoridades españolas. En este ambiente, el pasquín cumplió una significativa función comunicativa que se prolongó hasta inicios del siglo siguiente con mensajes radicales y ambiciosos.

La comunicación informal en el Perú tuvo múltiples expresiones escriturales. El "pasquín anónimo", de violenta expresión lingüística, fue una de ellas en una coyuntura de crisis política y económica que afectó a los criollos y mestizos de los espacios urbanos y rurales del sur andino, donde la población carecía de imprentas y periódicos para testimoniar sus inquietudes, reclamos y protestas públicas contra los abusos de las autoridades españolas. Estos impresos circulaban principalmente en la capital del Virreinato del Perú, libres del control y de la censura previa por parte de la Inquisición y la Real Audiencia.

El pasquín ya estuvo presente en Europa del siglo XV, proliferando intensamente en la España del siglo XVIII y en sus colonias americanas, particularmente en el Perú a consecuencia de las reformas borbónicas. Las movilizaciones campesinas de Granada mostraron sus violentas protestas mediante el "pasquín anónimo". Gonzáles Cruz (2009: 83) también refiere su presencia en Sevilla al mostrar un incisivo pasquín en forma de soneto, ridiculizando a Carlos de Austria, jefes militares y al ejército aliado:

¿¿Dónde se halla Estanope? Prisionero.

Y el Archiduque dónde? Está escondido.

Y el Guido? En un cerón está metido.

Y Atalaya? De Guido compañero.

Y el Exército? Tuvo el paradero

Que su arrojo tenía merecido;

Pues viéndose que estaba ya corrido,

El propio se metió en el matadero.

Corazón desleal, incorregible,

Que intenta ya tu bárbaro destino;

Si Dios al Rey Philipo da la mano?

Trae ya tu prensión por imposible,

Que no puede a un empeño tan divino

Resistencia hazer poder humano".

El pasquín peruano del siglo XVIII comprometió directamente a las autoridades administrativas y políticas que trataron de implementar las reformas borbónicas, pero también a sus emisores en una sociedad heterogénea y de múltiples referentes históricos. 
Algunos de sus emisores sociales fueron los protagonistas de esta comunicación informal, necesaria en un período de censuras, protestas y rebeliones urbanas y campesinas que proliferaron en el Alto y Bajo Perú. Mestizos y criollos fueron los principales emisores de los pasquines al manifestar una cierta cultura ilustrada en sus mensajes. Muchos de ellos participaban de la propia administración colonial, aunque no estaban de acuerdo con sus conductas políticas y económicas. Pese a que las autoridades oficiales trataron de frenar e impedir la existencia de los pasquines (por atentar contra la "paz social" y el orden público del Virreinato) el pasquín siguió con su violento ímpetu de denuncia, muchas veces semejante al libelo.

\section{Encuentro con el escenario histórico}

El siglo XVIII, conocido también como "Siglo de las Luces", es el tiempo de grandes cambios en Europa y en Hispanoamérica. Este siglo está signado culturalmente por la preferencia al estudio y desarrollo científico, artístico, económico, histórico y filosófico. El gran interés que existió fue configurar la aparición de un nuevo individuo bajo el signo de la racionalidad, concepción que no se hizo ajena a la monarquía española borbónica que dio la imagen de los déspotas ilustrados y la recepción del influjo del modelo francés.

Los Borbones concentraron múltiples poderes, imponiendo diversas medidas políticas y administrativas que consideraban oportunas para la reorganización del reino y sus colonias. Lo hicieron de acuerdo con el modelo de las potencias emergentes como Inglaterra y Francia que vivían el pleno apogeo europeo. Sus medidas causaron múltiples reacciones en España ${ }^{2}$ y en Hispanoamérica, produciendo una multitud de protestas e incluso movilizaciones sociales. La mejor manifestación comunicativa estuvo en el "pasquín anónimo", vieja técnica de comunicación social que escapó del control y la censura de las autoridades gubernamentales de turno, como la Inquisición, que ya había accionado drásticamente contra los libros que pretendían circular anónimamente e incluso contra la vida de sus autores.

Las colonias hispanoamericanas (como uno de los espacios económicos capaces de seguir abasteciendo con materias primas a España) cayeron bajo las medidas de renovación del sistema económico y administrativo, repercutiendo en los múltiples sectores sociales del Virreinato del Perú ${ }^{3}$, sobre todo en la economía andina, cuyo mercado se debilitaba constantemente al no poder competir con los productos traídos de ultramar; además de la implementación de impuestos de aduanas, tránsito y otros que generó un caldeado clima social que se acentuó por las nuevas medidas administrativas y políticas contra la

2 En Granada del siglo XVIII los pasquines constituyeron una rica fuente de información.

3 La corrupción y la injusticia contra la población indígena por parte de las autoridades españolas era muy evidente en el siglo XVIII, sobre todo por parte de los corregidores que imponían y cobraban impuestos. Al respecto el virrey Amat y Juniet expuso en 1776 al concluir su mandato lo siguiente: "El mal tratamiento de los miserables indios, su desolación y exterminio, objetos son que se presentan a la vista menos reflexiva y que no avisa y pronostican la total ruina de esta noble y gran parte del universo. El comercio y las violencias de los corregidores que puede decirse (sin que tenga lugar la ponderación), que talan a sangre y fuego estos ricos y hermosos campos, manifiesta una continua guerra a la sociedad, convertidos los nobles empleos de la rectitud y buen gobierno en lonjas y tabernas de usura e iniquidades, donde se vende y prostituye la justicia públicamente por la torpe vil mano de una codicia embriagada, a quien acompaña el poder y la autoridad' (Amat y Juniet, 1947: 820-821). 
autonomía comunal campesina, el reemplazo de los "caciques de sangre" por personas ajenas. Sin embargo, la medida de mayor trascendencia fue la creación del Virreinato del Río de la Plata (1776) y la Real Audiencia de Charcas que afectó a los antiguos territorios del Virreinato Peruano, profundizando los malestares sociales que se expandieron y se intensificaron en criollos, mestizos e indígenas por los nuevos y elevados impuestos fiscales. Las quejas llegaron hasta la Real Audiencia de Lima que casi siempre terminaba negando sus reclamos; aunque las autoridades españolas sabían que los impuestos eran injustos, poco o nada hicieron por evitarlo. Estos y otros problemas se acentuaron irreversiblemente a finales de la vida colonial.

El tenso y violento ambiente social que vivía el Virreinato del Perú en las últimas décadas del siglo XVIII revelaba un conjunto de contradicciones y coyunturas históricas que contribuirían, en décadas posteriores, a la catástrofe de la dominación española en el Perú y América. La ruptura del Estado con la Iglesia católica, al desafiar la importancia de su poder político, no era un buen signo para la corona española. La expulsión de los jesuitas en 1767 y la fragmentación de la clase dominante profundizaron la crisis política, económica y social del sur andino. En el Cuzco (1777 y 1778) se acentuaron los conflictos entre el obispo Juan Moscoso y el corregidor de Tinta, Antonio de Arriaga, mientras crecían las protestas escritas y orales que transcurrían de boca en boca, sin dejar de pulular los pasquines.

A partir de 1790, por iniciativa del virrey Francisco Gil de Taboada y Lemos, se dio auge a este periodismo como expresión comunicacional, antecediéndole las crónicas, relaciones, bandos, rumores, entre otros ${ }^{4}$, con La Gaceta de Lima (1743), El Diario de Lima (1790), El Mercurio Peruano (1791) y El Semanario Crítico (1791). Todos estos impresos conservaron características más o menos comunes en su formato (tamaño, composición gráfica y diseño). Pero este tardío e incipiente periodismo capitalino estuvo controlado por la censura previa de la Iglesia y el Estado, sin noticiar los constantes malestares sociales. Sin embargo, el pasquín burló el control oficial de la comunicación, recurriendo al anonimato, que impedía la identificación de su autor o autores, a diferencia de otras formas de comunicación informal.

\section{El anonimato}

El pasquín constituyó una poderosa arma escrita de agitación para sus autores que sabían y buscaban el poder de la opinión pública, desafiando a la autoridad a través del anonimato para seguir conservando su estatus político y social, a la vez que se salvaguardaban del control de la Real Audiencia y de la Inquisición. De ello no estuvo ausente el secreto entre

4 Raúl Porras Barrenechea (1970: 7) sostiene que en la Colonia no existieron periódicos. Las noticias sólo se transmitían de manera oral y comúnmente eran de carácter local, como aquellas llegadas desde España. En el fondo, estas ya no eran noticias puesto que llegaban tardíamente al Perú. Sin embargo, creemos que sí existieron periódicos en la Colonia, como La Gaceta de Lima, El Mercurio Peruano y El Semanario Crítico. Aunque la aparición de estos periódicos fue tardía en comparación a su incidencia en España y en otros países de Europa siglos atrás. 
los autores del pasquín que consistía en una forma de protección a la autoría ${ }^{5}$, es decir, sostenía una agrupación peligrosa que lindaba entre la verdad o la ficción contra alguien a quien responsabilizaban de actos cometidos o por cometer. El anonimato era un mecanismo útil de protección frente al poder de una sociedad colonial rígidamente jerarquizada.

Muchos pasquines escritos en verso breve, estaban anunciados en primera persona del plural ("nos", "sabemos", "estamos", "nuestra") denunciando queja o demanda y protesta contra la autoridad inmediata de alta jerarquía política o administrativa. El anonimato resaltó otro rasgo del pasquín que sus autores escondieron deliberadamente al protestar contra la autoridad política, administrativa y social que les afectaba directamente. Este anonimato mostraba la acción clandestina que les permitía guardar el secreto de su identidad ${ }^{6}$.

Los pasquines se colocaban durante la noche, en lugares estratégicos y poco visibles a la vigilancia oficial, evitándose así la identificación de su autor o autores y de las posibles acusaciones y condenas que podían caer sobre ellos. Estos anónimos estaban fijados con cera o engrudo o miga de pan o clavados en las paredes o puertas de las iglesias, sin tener hora ni día fijo para aparecer públicamente (Varillas, 2008: 29). Casi siempre aparecían o eran descubiertos en los primeros momentos del alba cuando algunas gentes difundían verbalmente su contenido en cafés, fondas, chicherías, picanterías y otros lugares públicos (Bacacorzo, 1972: 21-22). Las autoridades, al percatarse del pasquín, lo retiraban inmediatamente para que el resto de la población alfabeta (constituida comúnmente por criollos y mestizos) no lo leyera. Bacacorzo, refiriéndose al pasquín, afirmaba que en "algunas oportunidades importantes, un solo texto aparecía en varios lugares" (ápud Rosas Lauro, 2005: 146). Las autoridades españolas se desesperaban por identificar, conocer y sancionar a sus autores e impedir la lectura de estos, sin tener éxito alguno; viéndose a veces obligados a responder con otro pasquín.

No obstante, a finales del siglo XVIII seguía latente la imagen del inca con su perfil mesiánico y milenarista, como legítimo soberano americano. En algunos pasquines radicales del Río de la Plata también se hace notable el descontento, afirmando la presencia de Túpac Amaru II como "rey justiciero", cuestionando al monarca español como a los alcaldes y corregidores de la Audiencia de la Plata. En ese sentido, véase el pasquín cuyo autor anónimo se identifica pluralmente con el líder indígena cuzqueño:

5 Lo anónimo y lo secreto son dos caras de una misma moneda del lenguaje oculto que tuvo el pasquín. Su significado fue la fuerza de alguien o de aquellos que tuvieron la proeza y hasta la astucia de no ser conocidos públicamente y menos por parte de la autoridad de turno (visitador, corregidor, jefe aduanero, tesorero de la caja fiscal, entre otros). Gran parte de sus emisores fueron criollos y mestizos afectados por las reformas fiscales y que conocían de lo efectivo de este antiguo medio de comunicación siempre denunciante, amenazador y agresivo. La existencia del pasquín también estuvo presente durante la revolución de José Gabriel Condorcanqui (Túpac Amaru II) como también después de su derrota y de otros violentos acontecimientos de inicios del siglo siguiente. Esta forma de comunicación informal y anónima nutrió a todo un horizonte de inconformidad, sedición y hasta de conflicto social que traerá, en tiempo no muy breve, una ruptura histórica que permitirá la fundación de un nuevo régimen cargado de aventuras y sueños, compromisos y hasta deudas de las más disímiles.

6 En la Edad Moderna no faltó el anonimato literario. De acuerdo con Casasús, la anonimidad fue una gran tradición en Inglaterra, cuna del diario anónimo (ápud Silva Prada, 2005). 
"Nuestro Gabriel Inca vive, jurémosle pues por Rey, porque viene a ser en ley y lo que es suyo reciba. Todo indiano se aperciba a defender su derecho, porque Carlos con despecho a todos aniquila y despluma y viene a ser todo en suma robó al revés y al derecho. Tanto daño perpetrado vengará Augusto cumplido pues españoles han sido autores del mal causado, morirán con el Soldado, Alcaldes, Corregidores, ricos, pobres y oidores o no he de ser Túpac Amaru, oyr tributos doblados ver los repartos ingentes el clamor de tantas gentes, están los pueblos turbados; desde el Cuzco aligados advertir podéis vosotros si de Lupa y esos otros quieres los muertos vengar que no han de resucitar muriendo todos nosotros".

Muchos pasquines estuvieron nutridos de un mensaje justiciero que posiblemente también se transmitió oralmente en lengua nativa (quechua o aymara) en los diversos espacios andinos del sur. Damelas afirma que "la coronación del nuevo inca se extendía por rumores comentados en diferentes lugares de encuentro como las chicherías" (ápud Revilla, 2009: 40). Los pasquines mostraron sus ánimos beligerantes acerca de un nuevo orden del sistema colonial. El mensaje tupacamarista se hizo muy profuso en Charcas y en Río de la Plata, con diferentes versiones en otras partes del Alto y Bajo Perú. El visitador Areche sostenía, en una carta dirigida al Rey de España (5/VIII/1779) que los pasquines son "papeles ciegos que es fuerza no desaparecer tanto, siendo repetidos" (ibídem).

Sofocado el movimiento de Túpac Amaru II, los pasquines continuaron pegándose en los conventos de las ciudades andinas (como La Paz y Oruro, donde los malestares sociales continuaron) incitando un ambiente violento para el siglo siguiente, mediante denuncias y exigencias de cambio social.Muchos de estos pasquines continuaron existiendo profusamente en las dos primeras décadas del siglo XIX. Estos últimos se distribuyeron como volantes, conservando su anonimato y su escritura holográfica, aunque algunos aparecieron impresos. Todos ellos insistieron con sus afrentas contra alguna autoridad conocida.

Al instalarse las Cortes de Cádiz (1810) y al decretarse la libertad de imprenta, se promovieron periódicos y otros escritos de carácter liberal. Entre ellos El Peruano, editado 
por Guillermo del Río y otros que circularon en Lima. Pero esta "primavera periodística" duró muy poco. Tras la restauración monárquica de Fernando VII (1814) se eliminaron muchos derechos liberales, propiciándose una violenta represión contra los opositores en el Perú y en el resto de América. El periodismo liberal desapareció, cobrando nuevamente relieve el pasquín (esta vez bajo la modalidad de "comunicado" o "remitido") siempre como medio de agitación al tomar partido por las rebeliones anticoloniales.

El 25 de julio de 1822, cuando el general San Martín se dirigía hacia Guayaquil para entrevistarse con Simón Bolívar, surgió un alzamiento contra Bernardo de Monteagudo, uno de los hombres fuertes y con gran poder político en el nuevo régimen. El alzamiento estuvo promovido por criollos conservadores que hallaron eco en el cabildo de Lima, consiguiendo su destitución y deportación. Un pasquín publicado en Lima se tituló "Epitafio a D. Bernardo de Monteagudo":

"Yace aquí para siempre compatriotas

El honorable Inquisidor del Estado,

Protector de serviles y de idiotas

Y apresor de los buenos declarando

El pretendió tratamos como Ilotas

Y con no iluminarnos se ha vengado

Ideales liberales lo acabaron

Ideas liberales lo enterraron".

\section{La expresión}

El pasquín del siglo XVIII estaba escrito en verso o en prosa, otros se acompañaban de imágenes gráficas o dibujos. No faltaron aquellos pasquines que iniciaban cada verso con letra mayúscula o capital. En algunas oraciones, estas grafías se constituían en acrósticos alusivos al apellido al iniciar cada verso y la escritura de trazos rígidos que se encubrían deliberadamente de la escritura original. En efecto, los pasquines traían un lenguaje breve y puntual para ser leído, aprehendido, copiado, memorizado y hasta repetido, facilitando la difusión y comprensión de su mensaje. Su lectura sólo era para unos pocos monolingües (castellano) o bilingües (castellano quechua o castellano aymara), pero la oralidad también permitía extender su mensaje en un ámbito social donde la población analfabeta tenía como lengua común el quechua o el aymara.

Los pasquines estaban escritos por criollos y mestizos que también dominaban las lenguas vernaculares o nativas. Después difundían su mensaje en el universo urbano y rural donde se evidenciaba la inconformidad social ante el mal manejo del Gobierno colonial. Los pasquines sirvieron, por entonces, como efectiva arma de comunicación para mostrar la queja y contribuir a la concretización de la opinión pública. 


\section{El tono del pasquín}

El pasquín expresaba los estados de ánimo saturados, cargados de ironía y ansiedad de sus autores anónimos. Generalmente su tono se presentó en dos modalidades: el pasquín "de tono crítico" y el de "tono mesurado". Ambos tonos estuvieron presentes en el Alto y Bajo Perú, generando un gran impacto divulgativo.

a) El pasquín de tono crítico: casi siempre manifestó un tono enfático y directo. Fue significativa su presencia en el Alto y Bajo Perú (Charcas, La Paz, Puno, Cuzco, Arequipa, Moquegua y otros). Se abocó a la denuncia, infundiendo el miedo y el pánico social ${ }^{7}$ entre las autoridades españolas y sus familias. En la figura 1 se muestra un pasquín arequipeño (mediados del siglo XVIII) caracterizado por la sátira y la mofa, predisponiendo a los lectores a la revuelta:

Figura 1: pasquín dirigido al visitador Baltazar Sematnat.

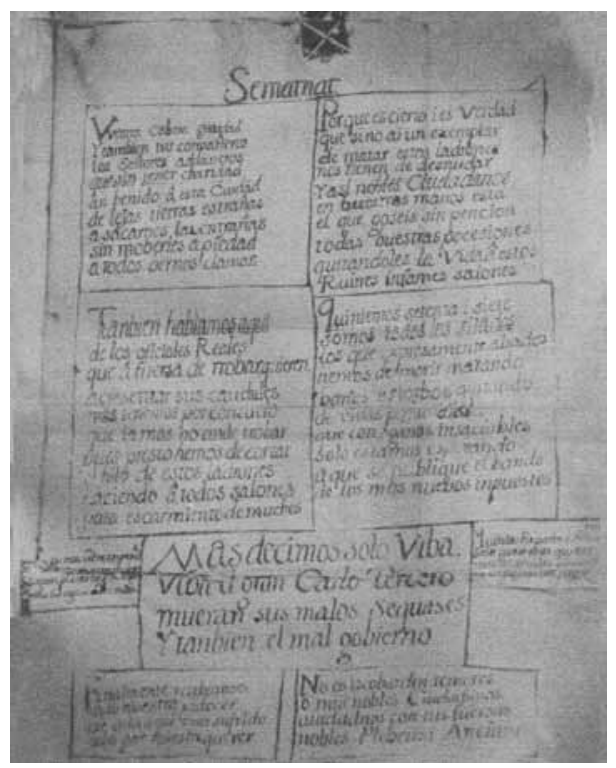

Fuente: archivo personal.

Las revueltas sociales en Arequipa (1779) hicieron que los pasquines incitaran a la rebelión contra las disposiciones gubernamentales y las autoridades ejecutoras (el visitador, el corregidor, jefes de aduanas y otros funcionarios de menor jerarquía) ya que se había confirmado el cobro de la nueva alcabala, perjudicando así a los criollos y mestizos que vendían y comercializaban sus productos en el sur andino. En aquel momento los pasquines criticaron la medida adoptada por el Gobierno, tal como podemos constatar en el siguiente ejemplo:

7 Por esas épocas, los limeños vivieron momentos de temor y miedo debido a factores naturales y sociales. En 1746 murieron en la capital más de mil trescientas personas a consecuencia de un terremoto. Lo mismo sucedió en el Callao por los efectos que ocasionó el posterior tsunami (ápud Rosas Lauro, 2005: 102-108). 


\begin{abstract}
"Vuestra cabeza guardad
y también tus compañeros

los señores aduaneros

que sin tener caridad

han benido a esta ciudad

de lejanas tierras extrañas

sin moberles a piedad

a todos bernos clamar".
\end{abstract}

El pasquín estuvo presente con un lenguaje acusatorio y sentencioso, cargado casi siempre de burla y sátira, denotando un tono agresivo, sentencioso y violento. Esta agresividad se hizo más incisiva y extensiva al tener diversas versiones y colocaciones en diversas partes de la ciudad de Arequipa, tal como ocurrió con otro pasquín amenazante contra Sematnat y Juan Bautista Pando (jefe de Aduanas), quien había viajado desde Lima con un grupo de funcionarios para cobrar los impuestos.

Los problemas políticos, económicos y sociales se agravaron conforme transcurrían las últimas décadas del siglo XVIII. Los pasquines ya no sólo denunciaban a las autoridades por los impuestos fiscales y otros, sino que también manifestaban su afán de cambio social y algunas medidas para lograr su concretización.

b) El pasquín de tono mesurado: raras veces el pasquín mostró mesura o pasividad en su mensaje. Si bien pudo atemperar su estilo, nunca dejó de lanzar quejas, amenazas y advertencias a las autoridades de turno. Siempre identificaba a su atacante con nombre propio, caricaturizando a sus opositores hasta el ridículo, sea por los defectos físicos, morales e intelectuales que estos poseyeran.

\title{
6. Composición formal del pasquín
}

Su estructura no fue homogénea: se presentó en verso o en prosa, acompañado con imágenes que se imponían en el texto escrito.

a) Pasquines en prosa: en el siglo XVIII e inicios del siglo XIX existieron pasquines escritos en prosa, pero fueron menos frecuentes que los compuestos en verso.

b) Pasquines en verso: recogieron las protestas sociales del Alto y Bajo Perú, conservando su estructura formal. Si bien no tuvieron intención estética, asimilaron algunos recursos literarios como esta pieza reseñada por Galdós Rodríguez (1967: 66):

"Quintos, repartos y aduanas

sólo queremos quitar

más los reales alcabalas".

No faltaron otros pasquines que tendrán un afán reconciliador como aquel pasquín publicado por el visitador Sematnat, quien muestra su destreza en la composición de versos: 
[1] "Pandito, Torres, Camborda

[2] son los que morirán conmigo.

[3] Y esto ha de ser sin remedio

[4] ojalá llegara la hora;

[5] pues nos tienen ya tan llenos

[6] que en acabado con ellos,

[7] no contentos con los tres,

[8] vuestro manejo al revés

[9] pagaréis en los infiernos.

[10] Solicite hablar conmigo

[11] el autor de este pasquín

[12] y sabemos con que fin

[13] promete ser nuestro amigo".

La composición poética formal contiene trece versos que están distribuidos por una novena y un cuarteto, cuya versificación muestra la rima siguiente:

$1^{\circ}$ con el $4^{\circ}$ verso

$2^{\circ}$ con el $3^{\circ}$ verso

$5^{\circ}$ con el $6^{\circ}$ y $9^{\circ}$ verso

$7^{\circ}$ con el $8^{\circ}$ verso

$10^{\circ}$ con el $13^{\circ}$ verso

$11^{\circ}$ con el $12^{\circ}$ verso

Las rimas de este pasquín son irregulares, como la distribución de sus versos y la disposición de su métrica poética. Por su forma no hay pretensión de rigurosidad literaria, quizás por la necesidad inmediata en una coyuntura histórica que se agravaba cada vez más. En todo caso, se revela conocimiento de la métrica poética y de la estructura formal.

Los recursos estilísticos del pasquín estaban bien definidos y codificados. Frecuentemente usaban las letras minúsculas al iniciar el verso, otras veces lo hacían con las letras mayúsculas o capitales. En la denominada "guerra de los pasquines", dirigido contra el visitador Sematnat, Galdós Rodríguez (1967: 119), cita una pieza que exhibe el uso de las mayúsculas en forma de acróstico:

"Toda llena de pensiones

Ello siempre morirás

Ay ¡Qué lastimoso día!

Es Pando y Palacios,

Camborda y Sematnat;

Otros también morirán.

Todo lo que insinuamos,

Advierte que en Arequipa,

Regocijados estamos.

Esto es si pretendes

Ser esta conformidad; 
No tienes unjo de parte

Todos en igualdad

Remítemelo afuera

A ese vizcaíno ladrón:

Rocín griego y empachado

$\mathbf{O}$ de vanidad llevado

¡Viva nuestro monarca!

Acábense los ladrones,

Reventados los cojones".

c) Pasquines con imágenes: aparecieron otros pasquines escritos que adjuntaban imágenes llamativas y sencillas, aunque impactantes comunicativamente y dirigidos a la conciencia social.

Los pasquines como forma de comunicación escrita (sea en prosa o verso) mantuvieron una denuncia crítica y sistemática contra las autoridades y el régimen colonial en general. No hay duda que contribuyeron a establecer un escenario de concientización social que desencadenaría posteriormente la Independencia del Perú.

\section{Fuentes consultadas}

- Amat y Juniet, M. (1947). Memorias de gobierno. Sevilla: Escuela de Estudios Hispanoamericanos de Sevilla.

- Bacacorzo, X. (1972). "El pasquín y su trascendencia en la lucha libertaria nacional". En Literatura de la emancipación hispanoamericana y otros ensayos. Lima: Instituto Internacional de Literatura Iberoamericana - Universidad Nacional Mayor de San Marcos.

- Carr, E. (1970). ¿Qué es la historia? Barcelona: Seix Barral.

- Certeau, M. (1993). La fábula mística. México D. F.: Universidad Iberoamericana.

- Chassin, J. (2008). El rol de los alcaldes indios en las insurrecciones andinas. Lima: Instituto Francés de Estudios Andinos.

- Flores Galindo, A. (1977). Arequipa y el Sur Andino: ensayo de historia regional (siglos $X V I I I-X X)$. Lima: Horizonte.

- Galdós Rodríguez, G. (1967). La rebelión de los pasquines. Un intento emancipador de Arequipa colonial. Arequipa: Universidad Nacional de San Agustín.

- Gargurevich Regal, J.

_(2002). La comunicación imposible. Lima: Universidad Nacional Mayor de San Marcos.

_(1999). “Anónimo y Revolución en Arequipa en el siglo XVIII”. Extraída el 2/X/2012 desde http://macareo.pucp.edu.edu.pe/jgargure/anonimos.htm

_(1991). Historia de la prensa peruana: 1594 -1990. Lima: La Voz. 
- Gonzáles Cruz, D. (2009). Propaganda e información en tiempos de guerra: España y América (1700-1714). Madrid: Silex.

- Losada, J. (2008). “El infierno de Flandes”. Historia y vida, núm. 488. Madrid.

- Porras Barrenechea, R. (1970). El periodismo en el Perú. Lima: Instituto Raúl Porras.

- Revilla, P. (2009). "Pasquines reformistas, pasquines sediciosos: aquellas hojas volanderas en Charcas (siglos XVIII y XIX)". Cultura, núms. 22-23. Extraída el 2/X/2012 desde http://www.revistasbolivianas.org.bo/pdf/rcc/v10n23/v10n23a03.pdf

- Romero, C. (1940). Los orígenes del periodismo en el Perú: de la relación al diario 1594-1790. Lima.

- Rosas Lauro, C. (ed.) (2005). El miedo en el Perú. Siglos XVIII al XIX. Lima: Pontificia Universidad Católica del Perú.

- Rowe, J. (1972). El movimiento nacional inca del siglo XVIII. Lima: Ideología Ayacucho.

- Ruiz Astiz, J. (2008). Literatura subversiva: líbelos y pasquines en el Reino de Navarra (1512-1808). Pamplona: Griso.

- Silva Prada, N. (2005). "La escritura anónima: ¿Especie sediciosa o estrategia de comunicación política colonial?”. Andes, núm. 16. Universidad Nacional de Salta.

- Torrico Pavozo, V. (1997). El pasquín en la Independencia del Alto Perú. Puebla: Plaza y Valdés.

- Vargas Ugarte, R. (1956). Historia del Perú y del Virreinato en el siglo XVIII (17001790). Lima: Tipografía Peruana.

- Varillas Montenegro, A. (2008). El periodismo en la historia del Perú: desde sus orígenes hasta 1850. Lima: Universidad de San Martín de Porres. 